\title{
Experimentation and Optimization of Shrinkage in Plastic Injection Molded GPPS Part
}

\author{
T. Bhirud ${ }^{1 *}$ and R. Metkar ${ }^{2}$ \\ ${ }^{1}$ PG Student, Government College of Engineering, Amravati, India \\ ${ }^{2}$ Government College of Engineering, Amravati, India \\ \{tejasdbhirud16@gmail.com, rajeshmetkar@yahoo.co.in\}
}

\begin{abstract}
The objective of this research is to find out the optimized process parameters for minimum shrinkage.For this purpose, the injection molded General Purpose Polystyrene (GPPS) part which is used in refrigerators is taken. The Taguchi method is used for design of experiments. For five parameters with three levels, L27 orthogonal array in case of Taguchi method is selected. The experiments are performed in Autodesk mold-flow insight simulation software with mold temperature, melt temperature, injection time, packing pressure and cooling time as process parameters. Analysis of variance is used to find out optimized set of process parameters and percentage effect of each parameter on shrinkage. Regression analysis is carried out to predict shrinkage value using regression equation. Artificial Neural Network (ANN) is used to predict shrinkage value for optimized process setting. Thus, experimental, statistical and computational approaches are used for validation of research.
\end{abstract}

Keywords: Moldflow plastics insight, Analysis of variance, Autodesk mold-flow insight, Signal to noise

\section{Introduction}

Plastic injection molding is widely used technology that converts plastics into products of various shapes and sizes. Fast growth of plastic industries made complex geometries to manufacture in single production step which results in mass production of plastic parts. The productivity, cycle time and energy consumption of the molding process is also influenced by molding conditions. Materials, part design and tooling develop a close relationship with molding conditions [1].

The quality of an injection molded part can be divided into three types: (1) dimensional characteristics, like weight, length and thickness; (2) surface properties, related to surface defect like sink marks, shrinkage, warpage, and flash; and (3) mechanical properties such as tensile and impact strengths. Optimized process parameters reduce the cycle time and increase the quality of the product [2]. The objective of work is to minimize shrinkage by optimizing process parameters affecting shrinkage using Taguchi method.

Chen and Huang studied the effect of process parameters on shrinkage and volumetric shrinkage at ejection using design of experiments technique [3]. The study of shrinkage and warpage for microcellular and conventional injection molding is done by Kramschuster et al. for box shaped polypropylene part [4]. Mirigul Altan has carried out shrinkage reduction by using Taguchi, analysis of variance (ANOVA) and neural network method for both PP and PS material separately [5]. Kamal et al. studied finite element analysis of residual thermal stresses in injection molded thermoplastic part [6].

Othman et al. used Taguchi method to optimize the process parameters that satisfy part qualities like shrinkage, warpage and ultimate tensile strength [7]. Andrisano et al. introduced Design of Simulation Experiments (DOSE) method that can be used to define optimal process parameters for better quality of the product [8]. Hao el al. found that simulation of thin walled parts using mold-flow [9]. Kurtaran et al. used neural network model and genetic algorithm to reduce the warpage of bus ceiling lamp base [10].

B. Iyer, S. Nalbalwar and R. Pawade (Eds.)

ICCASP/ICMMD-2016. Advances in Intelligent Systems Research.

Vol. 137, Pp. 107-112.

(C) 2017. The authors - Published by Atlantis Press

This is an open access article under the CC BY-NC license (http://creativecommons.org/licens)es/by-nc/4.0/).

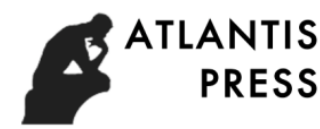




\subsection{Material}

The small refrigerator tray is used for this research which has the problem of shrinkage of material at the corner of the part. The problem of shrinkage occurred due to uneven cooling of the part. The small refrigerator tray is made of General Purpose Polystyrene (GPPS), the sub type of Polystyrene family. GPPS 1044 is the material of the part. This material is used in refrigerator tray, chilling tray and crisper tray etc. The part used for study is shown in Fig. 1. The properties of this material are summarized in Table 1.

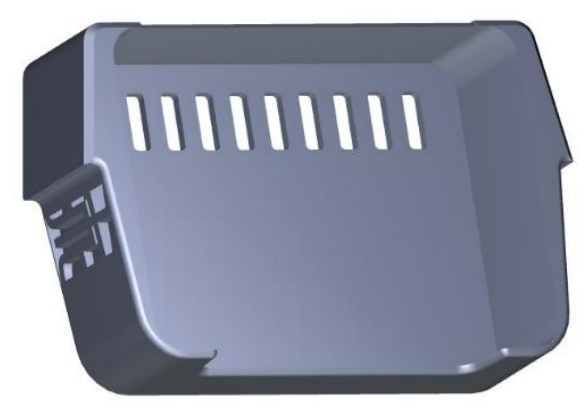

Fig. 1. Refrigerator Tray used for study

Table 1 Properties of GPPS 1044

\begin{tabular}{|l|l|}
\hline \multicolumn{1}{|c|}{ Properties } & \multicolumn{1}{c|}{ Values } \\
\hline Appearance & Solid Pellets \\
\hline Color & Lens \\
\hline Melting Point & $240^{\circ} \mathrm{C}\left(180-260^{\circ} \mathrm{C}\right)$ \\
\hline Mold Temperature & $40-60^{\circ} \mathrm{C}$ \\
\hline Relative Density & $1040-1130 \mathrm{~kg} / \mathrm{m} 3$ \\
\hline Young's Modulus & $3000-3500 \mathrm{MPa}$ \\
\hline Poisson's Ratio & 0.35 \\
\hline
\end{tabular}

\section{Experimental Work}

Design of experiment is technique to find optimized process designs by studying their effects on performance and solve production problems by laying out investigative experiments. For this study, experiment is designed by using Taguchi method. Table 2 shows process parameters with their three levels. For the study of five process parameters with three levels, 243 experiments are to be carried out. But it is not possible to simulate all experiments. Hence, L27 orthogonal array is selected using Taguchi approach.

Table 2 Process parameters with their levels

\begin{tabular}{|c|c|c|c|c|c|}
\hline \multirow{2}{*}{ Level } & \multicolumn{5}{|c|}{ Experimental Factors } \\
\cline { 2 - 6 } & $\begin{array}{c}\text { Melt } \\
\text { temperature } \\
\left({ }^{\circ} \mathbf{C}\right)\end{array}$ & $\begin{array}{c}\text { Mold } \\
\text { temperature }\left({ }^{\circ} \mathbf{C}\right)\end{array}$ & $\begin{array}{c}\text { Injection time } \\
(\mathbf{s})\end{array}$ & $\begin{array}{c}\text { Packing } \\
\text { pressure (MPa) }\end{array}$ & $\begin{array}{c}\text { Cooling time } \\
(\mathbf{s})\end{array}$ \\
\hline 1 & 250 & 40 & 10 & 30 & 20 \\
\hline 2 & 260 & 50 & 11 & 40 & 25 \\
\hline 3 & 270 & 60 & 12 & 50 & 30 \\
\hline
\end{tabular}

Autodesk mold-flow insight provided the properties of GPPS through material database. Single cavity analysis with 3D mesh is used for meshing of the part. The part consists of tetrahedral elements. The part is analyzed for solving pressure, flow and temperature parameters. The process parameters selected for shrinkage analysis are melt temperature, mold temperature, injection time, packing pressure and cooling time and are represented by "MP”, "MT”, "IT", "PP”, “CT” respectively. The experiments are performed for all sets of process parameters 
and are shown in Table 3 along with shrinkage values and $\mathrm{S} / \mathrm{N}$ ratio values. "Fill+ Pack+ Warp" analysis sequence is used. The packing time is kept constant as $15 \mathrm{~s}$ for all cases. Other machine and process parameters are kept as default. The shrinkage analysis result of one result is shown in Fig. 2.
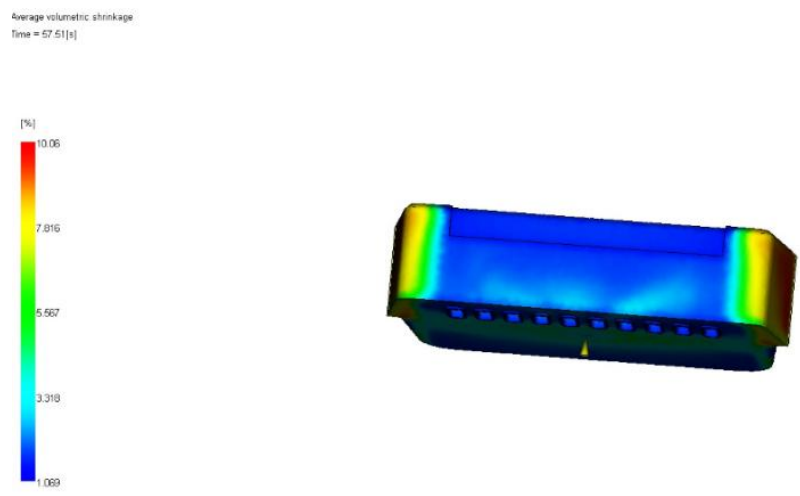

Fig. 2. Shrinkage analysis result of refrigerator tray mold

\section{Results and Discussion}

\subsection{Taguchi Method}

The Taguchi method is applied to design of experiment to determine the effect of each process parameter on shrinkage. The shrinkage values obtained from MPI are put in MINITAB V17 software manually and S/N ratios are calculated. "Smaller the better" characteristic is preferred to get $\mathrm{S} / \mathrm{N}$ ratios as the goal of study is to minimize shrinkage. The shrinkage values with $\mathrm{S} / \mathrm{N}$ ratios is shown in Table 3. Response table for $\mathrm{S} / \mathrm{N}$ ratios is shown in Table 4. By analyzing graph and table, the best set of process parameters is obtained. The best set of process parameters is $\mathrm{MP}=250, \mathrm{MT}=40, \mathrm{PP}=50, \mathrm{IT}=11$ and $\mathrm{CT}=25$. Confirmation test is performed to determine optimal conditions.

\subsection{Analysis of Variance (ANOVA)}

ANOVA is applied to experimental design in order to determine the significance of each parameter on shrinkage. P-value less than 0.05 indicates that the process parameter has significant effect on shrinkage as shown in Table 5. ANOVA helps to determine the percentage effect of each parameter on shrinkage and also shows which parameter is most significant among all parameters. Response graphs for S/N ratio are plotted using data in Table 5 and shown in Fig. 3. To determine the percentage effect of each parameter following formula is used:

$\%$ Effect of each parameter $=\frac{\text { SS of parameter }}{\text { Total SS }}(1)$

Where $\mathrm{SS}=$ Sum of Squares

Table 3 Process Settings with corresponding Shrinkage Values and S/N Ratios

\begin{tabular}{|c|c|c|c|c|c|c|c|}
\hline Sr. & MP & MT & IT & PP & CT & Shrinkage & S/N \\
\hline 1 & 250 & 40 & 10 & 30 & 20 & 0.699 & 3.11046 \\
\hline 2 & 250 & 40 & 10 & 30 & 25 & 0.6946 & 3.1653 \\
\hline 3 & 250 & 40 & 10 & 30 & 30 & 0.8488 & 1.4239 \\
\hline 4 & 250 & 50 & 11 & 40 & 20 & 0.9024 & 0.8920 \\
\hline 5 & 250 & 50 & 11 & 40 & 25 & 0.8871 & 1.0405 \\
\hline 6 & 250 & 50 & 11 & 40 & 30 & 0.9024 & 0.8920 \\
\hline 7 & 250 & 60 & 12 & 50 & 20 & 1.061 & -0.5143 \\
\hline
\end{tabular}




\begin{tabular}{|c|c|c|c|c|c|c|c|}
\hline 8 & 250 & 60 & 12 & 50 & 25 & 1.069 & -0.5795 \\
\hline 9 & 250 & 60 & 12 & 50 & 30 & 1.069 & -0.5795 \\
\hline 10 & 260 & 40 & 12 & 40 & 20 & 0.7342 & 2.6837 \\
\hline 11 & 260 & 40 & 12 & 40 & 25 & 0.7342 & 2.6837 \\
\hline 12 & 260 & 40 & 12 & 40 & 30 & 0.7387 & 2.6306 \\
\hline 13 & 260 & 50 & 10 & 50 & 20 & 0.8479 & 1.4331 \\
\hline 14 & 260 & 50 & 10 & 50 & 25 & 0.8477 & 1.4351 \\
\hline 15 & 260 & 50 & 10 & 50 & 30 & 0.8488 & 1.4238 \\
\hline 16 & 260 & 60 & 11 & 30 & 20 & 0.91 & 0.8191 \\
\hline 17 & 260 & 60 & 11 & 30 & 25 & 0.91 & 0.8191 \\
\hline 18 & 260 & 60 & 11 & 30 & 30 & 0.91 & 0.8191 \\
\hline 19 & 270 & 40 & 11 & 50 & 20 & 0.6687 & 3.4953 \\
\hline 20 & 270 & 40 & 11 & 50 & 25 & 0.6741 & 3.4255 \\
\hline 21 & 270 & 40 & 11 & 50 & 30 & 0.6737 & 3.4306 \\
\hline 22 & 270 & 50 & 12 & 30 & 20 & 0.9208 & 0.7166 \\
\hline 23 & 270 & 50 & 12 & 30 & 25 & 0.9288 & 0.6415 \\
\hline 24 & 270 & 50 & 12 & 30 & 30 & 0.7611 & 2.3711 \\
\hline 25 & 270 & 60 & 10 & 40 & 20 & 1.065 & -0.5469 \\
\hline 26 & 270 & 60 & 10 & 40 & 25 & 1.051 & -0.5469 \\
\hline 27 & 270 & 60 & 10 & 40 & 30 & 1.065 & -0.5469 \\
\hline
\end{tabular}

Table 4 Response Table for Signal to Noise Ratios

\begin{tabular}{|c|c|c|c|c|c|}
\hline Level & MP & MT & PP & IT & CT \\
\hline 1 & 0.98342 & 2.89436 & 1.54295 & 1.16286 & 1.34325 \\
\hline 2 & 1.63864 & 1.20513 & 1.03296 & 1.73707 & 1.35548 \\
\hline 3 & 1.39499 & -0.08244 & 1.44114 & 1.11712 & 1.31832 \\
\hline Delta & 0.65521 & 2.97680 & 0.51000 & 0.61996 & 0.03716 \\
\hline
\end{tabular}

Table 5 ANOVA Result Table for Shrinkage

\begin{tabular}{|l|l|l|l|l|l|l|}
\hline \multicolumn{1}{|c|}{ Factor } & $\mathbf{D}_{\mathbf{f}}$ & \multicolumn{1}{c|}{ SS } & \multicolumn{1}{c|}{ MS } & F-value & P-value & PC (\%) \\
\hline Melt Temperature & 2 & 0.023602 & 0.011801 & 5.61 & 0.014 & 4.89 \\
\hline Mold Temperature & 2 & 0.388632 & 0.194316 & 92.40 & 0.000 & 80.5 \\
\hline Injection time & 2 & 0.014097 & 0.007049 & 3.35 & 0.061 & 2.9 \\
\hline Packing Pressure & 2 & 0.022860 & 0.011430 & 5.44 & 0.016 & 4.73 \\
\hline Cooling Time & 2 & 0.000025 & 0.000012 & 0.01 & 0.994 & 0.005 \\
\hline Error & 16 & 0.033646 & 0.002103 & & & 6.9 \\
\hline Total & 26 & 0.482863 & & & & 100.00 \\
\hline
\end{tabular}




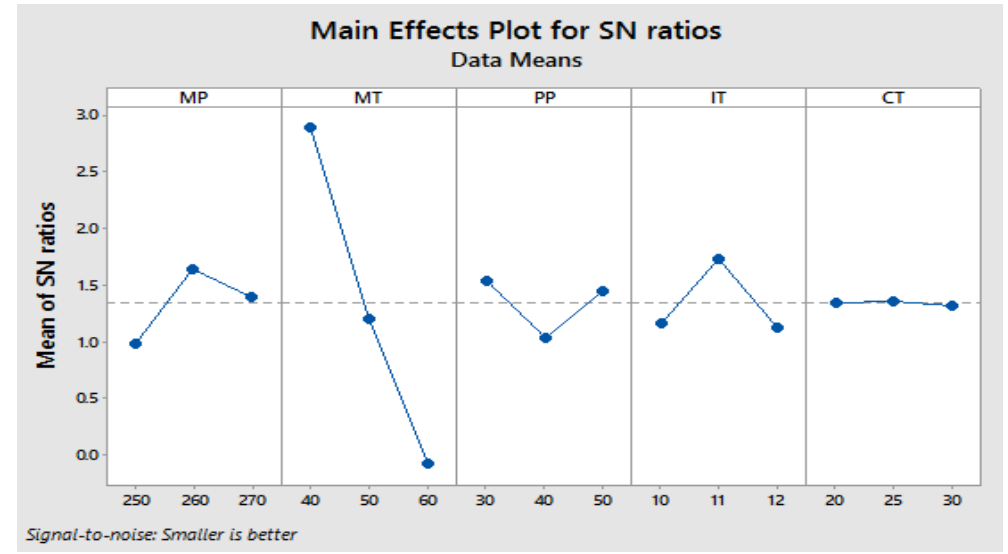

Fig. 3. Response graphs for $\mathrm{S} / \mathrm{N}$ ratios

\subsection{Regression Analysis}

Regression analysis is used to define the relationship between a response variable and one or more predictors. The mathematical relationship is formulated between shrinkage value and five process parameters selected for study. Regression analysis is done by using MINITAB V17 software. This model is used directly to predict the values of shrinkage from a new set of input parameters. The mathematical relation obtained from regression analysis is given below:

$\mathrm{S}=0.481-0.00181 \mathrm{MP}+0.01469 \mathrm{MT}+0.0098 \mathrm{IT}+0.00027 \mathrm{PP}+0.00009 \mathrm{CT}$

The correlation coefficient measures the goodness of fit between the simulation data and predicted values. The $\mathrm{R}^{2}$ value is found to be $82.04 \%$. Also, the adjacent $\mathrm{R}^{2}$ value is found to be $77.76 \%$. These values show that predicted shrinkage values have good correlation with shrinkage values obtained from simulation. Hence the regression model is acceptable.

\subsection{Artificial Neural Network}

Neural network system is used to predict the shrinkage value for the two sets of process parameters, one is recommended setting provided by MPI and other is optimized process parameter setting. It is found that the predicted shrinkage value for optimized process setting is less than that for recommended process setting as shown in Table 6.

MATLAB nntool function is used for this study. A feed-forward back-propagation neural network model with 5-10-1-1 network is created and trained.

Table 6 Comparison of shrinkage values for design of experiment by Taguchi method

\begin{tabular}{|l|l|l|l|l|l|l|l|l|}
\hline & MP & MT & PP & IT & CT & $\begin{array}{l}\text { Simulated } \\
\text { shrinkage }\end{array}$ & $\begin{array}{l}\text { Regression } \\
\text { analysis }\end{array}$ & $\begin{array}{l}\text { Neural } \\
\text { network }\end{array}$ \\
\hline Mold-flow recommended process & 250 & 60 & 12 & 50 & 25 & 1.069 & 1.069 & 1.069 \\
\hline Optimized process setting & 250 & 40 & 11 & 50 & 25 & 0.7546 & 0.749 & 0.7705 \\
\hline
\end{tabular}

\section{Conclusions}

In the proposed research, Taguchi method is found to be more efficient, user friendly and accurate. From the ANOVA table obtained by Taguchi, mold temperature is found to be more effective process parameter with effect of $80.5 \%$ followed by melt temperature and packing pressure with effect of $4.89 \%$ and $4,73 \%$ respectively. For Taguchi method, the shrinkage value obtained in mold-flow recommended setting is reduced by $29.9 \%$ after optimization. 
The shrinkage value predicted by neural network model for optimized process parameter setting is less as compared to that of recommended setting by MPI. This shows that the optimization is correct. While comparing, the values obtained by mold-flow plastic insight, regression analysis and neural network model, it is seen to be good agreement between with each other.

\section{References}

[1]. Xuan- Phuong dang 'General Frameworks for Optimization of Plastic Injection Molding Process Parameters', Journal of Simulation Modeling Practice and Theory, vol. 41(2014), pp.15-27.

[2]. Yi Yang, Bo Yang, Shengqiang Zhu, Xi Chen, "Online quality optimization of the injection molding process via digital image processing and model-free optimization", Journal of Materials Processing Technology, No. 226(2015), pp. 85-98.

[3]. Wu-Lin Chen, Chin-Yin Huang and Ching-Ya Huang, "Finding efficient frontier of process parameters for plastic injection molding", journal of Industrial Engineering International, pp. 1-11(2013).

[4]. Adam Kramschuster, Ryan Cavitt, Donald Ermer, Zhongbao Chen and Lih-Sheng Turng, "Quantitative study of shrinkage and warpage behaviour for microcellular and conventional injection molding", Polymer Engineering and Science, pp. 1408-1418(2005).

[5]. Mirigul Altan 'Reducing Shrinkage in Injection Moldings via the Taguchi, ANOVA and Neural Network Methods', Journal of Materials and Design, vol.31(2010), pp. 599-604.

[6]. Musa R. Kamal, Avraam Isayev, Shih-Jung Liu, "Injection molding- technology and fundamentals", Hanser Publishers, Munich (2009).

[7]. Othman, Mohd Hilmi and m. Amin, Sri Yulis, 'Optimising Injection Moulding parameters that satisfies part qualities by using Taguchi Method', IEEE, Business, Engineering \& Industrial Applications colloquium (BEIAC), PP. 307-312(2012).

[8]. A. O. Andrisano, F. Gherardini, F. Leali, M. Pellicciari and A. Vergnano, 'Design of Simulation Experiments method for Injection Molding Process Optimization', International Conference on Innovative Methods in Product Design, pp. 476-486(2011).

[9]. Zhu Hao, Wang Chuanyang, Shen Jian, "Analysis of Injection Molding of Thin- walled Parts Based on Moldflow", International Conference on Digital Manufacturing \& Automation, pp. 193-195(2011).

[10]. Hasan Kurtaran, Babur Ozcelik and Tuncay Erzurumlu, 'Warpage Optimization of a Bus Ceiling Lamp Base using Neural Network model and Genetic Algorithm', Journal of Materials Processing Technology, vol. 169(2005), pp. 314-319. 